\title{
ENSINO DE LÍNGUA INGLESA PARA ALUNOS SURDOS ${ }^{1}$
}

\author{
Eleyne Deyannys de Sousa Silva ${ }^{2}$ \\ Francisca Neuza de Almeida Farias ${ }^{3}$ \\ Universidade Estadual do Piauí - UESPI
}

\section{RESUMO}

Esta é uma pesquisa do tipo revisão sistemática, na qual procuramos analisar estudos sobre o ensino de Inglês para alunos surdos (em escolas regulares ou bilíngues). Após busca na plataforma Google Scholar (Academics), utilizando descritores específicos e aspas como delimitador ("Ensino de Inglês para Surdos"), encontramos 15 (quinze) pesquisas, das quais cinco se mostraram alinhadas com os objetivos do nosso trabalho. Os objetivos deste estudo são investigar se os professores utilizam técnicas e métodos de ensino diferenciados para alunos surdos, quais estes métodos e qual o impacto destes no processo de ensino aprendizagem deste aluno. Após leitura rigorosa dos trabalhos selecionados, concluímos que apesar dos avanços nas políticas educacionais inclusivas, mesmo as escolas bilíngues não têm condições apropriadas para que este público, de fato, seja incluído. Faltam treinamentos para os professores, materiais didáticos apropriados, a metodologia de ensino ainda é voltada quase que exclusivamente para o aluno ouvinte, os discentes ouvintes, normalmente, não conhecem a Libras e, portanto, interagem muito pouco com os alunos surdos, além de faltarem intérpretes de Libras nas escolas que têm alunos surdos matriculados. Destacamos também que em todos os casos nos quais os professores tinham conhecimento de Libras, e treinamento acerca das especificidades dos discentes com surdez, a metodologia de ensino foi realizada de forma diferenciada, proporcionando um melhor aprendizado e possibilitando a inclusão do aluno surdo na escola.

Palavras-Chave: Surdez. Aprendizagem. Língua Inglesa. Libras.

\section{INTRODUÇÃO}

Neste trabalho faremos uma revisão sistemática acerca do ensino de Língua Inglesa para estudantes surdos. Para tanto, iremos considerar como L1 desta população, a Língua de Sinais, e como L2, a Língua Portuguesa escrita e como LE (Língua Estrangeira), a Língua Inglesa.

\footnotetext{
1 Trabalho apresentado no Congresso Brasileiro Ciência e Sociedade (CBCS 2019), promovido pelo Centro Universitário Santo Agostinho, de 03 a 05 de outubro de 2019, em Teresina-PI.

${ }^{2}$ Graduanda do Curso de Licenciatura Plena em Letra Inglês - UESPI, voluntária do PIBIC-UESPI, integrante do Grupo de Estudos em Língua de Sinais - GELSPI / UESPI. E-mail: eleynehu@outlook.com.

${ }^{3}$ Doutora em Educação (UFPI), professora do curso de Letras da Universidade Estadual do Piauí - UESPI, coordenadora do Grupo de Estudos em Língua de Sinais - GELSPI / UESPI. E-mail: neuzafarias@yahoo.com.br.
} 
ANAIS CBCS 2019 | 3 a 5 de outubro de 2019 | Centro Universitário Santo Agostinho - Teresina - P

Desde a publicação da Lei no 9.394 de 20 de dezembro de 1996, quando foram estabelecidas as diretrizes e bases da educação nacional (LDB), começaram a ocorrer grandes mudanças na educação dos estudantes com necessidades especiais, pois essa lei previa que eles deveriam ser incluídos, preferencialmente, no ensino regular, trazendo no seu Capítulo V - da Educação Especial - as orientações gerais para este acesso (BRASIL, 1996).

Posteriormente, foram sancionadas leis relacionadas à comunidade surda, como a Lei $\mathrm{n}^{\circ}$ 10.436, de 24 de abril de 2002, regulamentada pelo Decreto $n^{\circ} 5.626$ de 22 de dezembro de 2005, que promoveu um grande avanço para a luta dos surdos, pois reconheceu a Libras como uma língua natural e obrigou os sistemas educacionais Federal, do Distrito Federal, Estaduais e Municipais a garantirem a inclusão

nos cursos de formação de Educação Especial, de Fonoaudiologia e de Magistério, em seus níveis médio e superior, do ensino da Língua Brasileira de Sinais - Libras, como parte integrante dos Parâmetros Curriculares Nacionais - PCNs, conforme legislação vigente. (BRASIL, 2002 e 2005).

Frente a esse novo desafio para os docentes das escolas regulares, precisamos ter em mente quais as necessidades do aluno surdo, uma vez que, segundo Paulo Freire (1979, p. 19): “para ser válida, toda educação, toda ação educativa deve necessariamente estar precedida de uma reflexão sobre o homem e de uma análise do meio de vida concreto do homem concreto a quem queremos educar (ou melhor dito: a quem queremos ajudar a educar-se".

Considerando que já se passaram vários anos desde que este arcabouço jurídico foi sancionado, e que os estudantes surdos têm sido matriculados preferencialmente nas escolas regulares, esta pesquisa visa a produção acadêmica sobre o ensino de Língua Inglesa para esses alunos. Nesse sentido, entendemos, em consonância com a bibliografia pesquisada, que são necessárias técnicas e estratégias de ensino adaptadas às necessidades desses estudantes, exigindo dos professores e professoras das escolas regulares novos conhecimentos e práticas.

Não podemos perder de vista ainda que estamos falando de mais de nove milhões de pessoas surdas, segundo o censo do Instituto Brasileiro de Geografia e Estatística (IBGE) de 2010 (BRASIL, 2012). 


\section{conghESSO CIENCIAESOCIEDADE \\ Inovação, Diversidaade e Sustentahililitaile}

ANAIS CBCS 2019 | 3 a 5 de outubro de 2019 | Centro Universitário Santo Agostinho - Teresina - PI

Portanto, o objetivo geral desta pesquisa é analisar os trabalhos que tratam do ensino da Língua Inglesa para estudantes surdos. Os objetivos específicos são: analisar se os professores utilizam técnicas diferenciadas para o ensino do Inglês para alunos surdos; descrever as técnicas empregadas no ensino do Inglês para esses estudantes; conhecer os resultados do uso destas técnicas no aprendizado do Inglês e identificar as dificuldades e os desafios para que o processo ensino-aprendizagem aconteça da forma almejada.

\section{METODOLOGIA}

Esta revisão sistemática da literatura tem por objetivo reunir estudos semelhantes a respeito do ensino de Inglês para surdos, publicados, em língua portuguesa, de 2015 a 2019, na plataforma Google Scholar (Academics), avaliando-os criticamente em sua metodologia, nos resultados encontrados e nas suas conclusões. "Por sintetizar estudos primários semelhantes e de boa qualidade"(ATALLAH e CASTRO, 1998), consideramos esta metodologia ideal para avaliar, especialmente, o interesse dos acadêmicos e pesquisadores sobre o ensino de língua estrangeira para pessoas surdas.

A seleção dos artigos para esta pesquisa ocorreu no dia 16 de agosto de 2019, em várias bases de dados, como a Lilacs e Medline, utilizando os seguintes descritores: ensino de inglês, ensino de língua inglesa, surdos. Diante dos resultados pífios, optamos pelos procedimentos de busca no Google Scholar, cujo banco de dados indexados reúne artigos acadêmicos de outras bases de dados, constituindo-se, portanto, em uma excelente ferramenta de busca em variados periódicos.

Nessa plataforma, executamos uma primeira busca usando palavras-chave: ensino de inglês + surdo e obtivemos, aproximadamente, 17.500 resultados em 0,03 seg. Na utilização de descritores mais específicos, desta vez, usando as aspas como delimitador: "ensino de inglês para surdos", obtivemos, aproximadamente, 15 resultados em 0,14 seg. Após a leitura dos resumos, foram selecionadas 5 pesquisas para análise. 


\section{conweESSOO CIENCIAESOCIEDADE

ANAIS CBCS 2019 | 3 a 5 de outubro de 2019 | Centro Universitário Santo Agostinho - Teresina - P

Fluxograma da pesquisa - Procedimentos de busca e resultados

Busca com os descritores Ensino de Inglês, Ensino de Língua Inglesa, Surdos:

\section{$\mathbf{1 7 . 5 0 0}$ resultados}

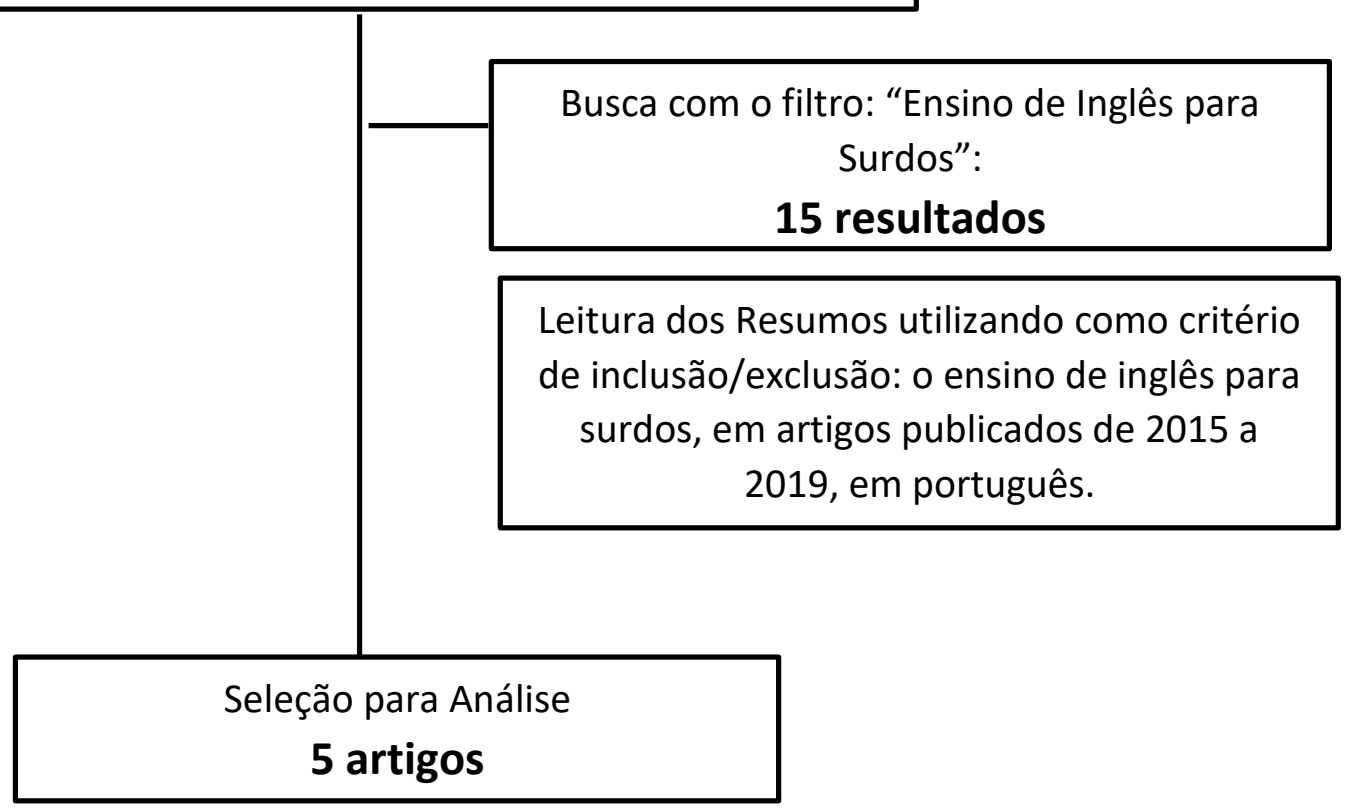

Fonte: fluxograma elaborado pelas autoras

\section{RESULTADOS E DISCUSSÃO}

Tabela 1 - Caracterização dos Estudos

\begin{tabular}{|c|c|c|c|}
\hline Autores/as & Título do Artigo & $\begin{array}{c}\text { Tipologia do } \\
\text { Estudo }\end{array}$ & Desenho metodológico \\
\hline $\begin{array}{l}\text { Yohanna Hemilly } \\
\text { Katleen Kühl e } \\
\text { Didiê Ana Ceni } \\
\text { Denardi }\end{array}$ & $\begin{array}{l}\text { Um olhar sobre ensino- } \\
\text { aprendizagem de língua } \\
\text { inglesa para surdos }\end{array}$ & $\begin{array}{l}\text { Pesquisa } \\
\text { qualitativa- } \\
\text { etnográfica }\end{array}$ & $\begin{array}{l}\text { - O estudo utilizou-se da } \\
\text { observação de seis aulas de } \\
\text { inglês em uma turma de } \\
\text { terceiro ano do Ensino Médio } \\
\text { do período matutino no ano de } \\
2015 . \\
\text { - Ao final, foi utilizada uma } \\
\text { questão do ENEM para } \\
\text { comparar o nível de } \\
\text { compreensão entre um aluno } \\
\text { surdo e um ouvinte. }\end{array}$ \\
\hline
\end{tabular}


ANAIS CBCS 2019 | 3 a 5 de outubro de 2019 | Centro Universitário Santo Agostinho - Teresina - P

\begin{tabular}{|c|c|c|c|}
\hline $\begin{array}{l}\text { Jubileia Mendes de } \\
\text { Matos Coelho e } \\
\text { Dánie Marcelo de } \\
\text { Jesus }\end{array}$ & $\begin{array}{l}\text { Práticas de letramento em } \\
\text { língua inglesa com alunos } \\
\text { surdos em contexto de } \\
\text { estágio supervisionado }\end{array}$ & $\begin{array}{l}\text { Pesquisa } \\
\text { qualitativo- } \\
\text { interpretativista }\end{array}$ & $\begin{array}{l}\text { - As pesquisadoras } \\
\text { compararam as estratégias } \\
\text { utilizadas durante as aulas de } \\
\text { dois grupos de professoras- } \\
\text { alunas do curso de Letras } \\
\text { Inglês (as docentes observadas } \\
\text { sabem se comunicar por meio } \\
\text { da Libras) para duas turmas de } \\
\text { alunos surdos em uma escola } \\
\text { pública da região; foram } \\
\text { realizadas filmagem de aulas, } \\
\text { entrevistas, questionário e } \\
\text { observação participativa. }\end{array}$ \\
\hline $\begin{array}{l}\text { Márcia de Moura } \\
\text { Gonçalves-Penna e } \\
\text { Simone de Jesus } \\
\text { Padilha }\end{array}$ & $\begin{array}{l}\text { Processos interativos entre } \\
\text { professora ouvinte e } \\
\text { estudantes visuais em aula } \\
\text { de língua inglesa }\end{array}$ & $\begin{array}{l}\text { Relato } \\
\text { de Experiência }\end{array}$ & $\begin{array}{l}\text { - O relato de experiência é } \\
\text { sobre o Projeto Piloto } \\
\text { intitulado "Curso de Inglês para } \\
\text { o Acadêmico Surdo" (a turma } \\
\text { era mista, formada por } \\
\text { acadêmicos do curso de Letras } \\
\text { Libras, sendo } 5 \text { alunos surdos e } \\
2 \text { ouvintes); } \\
\text { - Foram observados os } \\
\text { processos de interação tecidos } \\
\text { ao longo das aulas deste curso, } \\
\text { analisando-se as impressões } \\
\text { dos relatos da } \\
\text { estudante/professora/tutora. }\end{array}$ \\
\hline \multirow[t]{2}{*}{$\begin{array}{l}\text { Edvanilda Antônia } \\
\text { Borges e } \\
\text { Layane Rodrigues de } \\
\text { Lima }\end{array}$} & $\begin{array}{l}\text { O ensino e o aprendizado do } \\
\text { inglês como língua } \\
\text { estrangeira em uma escola } \\
\text { bilíngue para surdos: } \\
\text { reflexões sobre a prática } \\
\text { pedagógica. }\end{array}$ & $\begin{array}{l}\text { Pesquisa de } \\
\text { campo }\end{array}$ & $\begin{array}{l}\text { - Foram realizadas observações } \\
\text { de aulas, realizadas entrevistas } \\
\text { e aplicados questionários a } \\
\text { quatro estudantes surdos e a } \\
\text { duas professoras de inglês } \\
\text { (uma delas fluente em Libras) } \\
\text { de uma escola bilíngue; } \\
\text { - A coleta de dados ocorreu } \\
\text { durante o mês de agosto do } \\
\text { ano de } 2015 \text {, em duas turmas, } \\
\text { sendo uma do Ensino } \\
\text { Fundamental e a outra do } \\
\text { Ensino Médio. }\end{array}$ \\
\hline & & & $\begin{array}{l}\text { - A pesquisa foi realizada em } \\
\text { uma escola de ensino }\end{array}$ \\
\hline
\end{tabular}




\section{cONGERESOO CIENCIAESOCIEDADE

ANAIS CBCS 2019 | 3 a 5 de outubro de 2019 | Centro Universitário Santo Agostinho - Teresina - P

\begin{tabular}{|l|l|l|l|}
\hline $\begin{array}{l}\text { Gideão da Silva } \\
\text { Nascimento dos }\end{array}$ & $\begin{array}{l}\text { Pesquisa } \\
\text { qualitativa de } \\
\text { Francisca Maria } \\
\text { Cerqueira da Silva }\end{array}$ & $\begin{array}{l}\text { funho } \\
\text { exploratório } \\
\text { que se } \\
\text { configura comontal, no município de } \\
\text { um estudo de } \\
\text { caso }\end{array}$ & $\begin{array}{l}\text { - Os sujeitos da pesquisa foram } \\
\text { um aluno surdo e uma } \\
\text { professora. Foi realizada uma } \\
\text { entrevista com a professora de } \\
\text { inglês e feita observação em } \\
\text { uma aula de inglês ministrada } \\
\text { por ela. }\end{array}$ \\
\hline
\end{tabular}

Fonte: tabela elaborada pelas autoras

Os trabalhos analisados nesta pesquisa fizeram uso de diferentes metodologias para chegarem aos seus resultados. No trabalho 1 ("Um olhar sobre ensino-aprendizagem de língua inglesa para surdos"), verificamos que as pesquisadoras, além de procederem uma observação direta das aulas de inglês para surdos em uma escola, preocuparam-se em comparar o nível de compreensão entre um aluno surdo e um ouvinte, utilizando um texto em inglês retirado do Exame Nacional do Ensino Médio (Enem). As pesquisadoras perceberam, pelas respostas subjetivas dos alunos, que o ouvinte conseguiu ter um entendimento mais aprofundado acerca do tema abordado do que o surdo.

No trabalho 2 ("Práticas de letramento em língua inglesa com alunos surdos em contexto de estágio supervisionado"), as pesquisadoras observaram discentes do curso de Licenciatura em Letras Inglês durante o estágio supervisionado buscando conhecer as técnicas e métodos utilizados por elas em turmas de alunos surdos e os resultados das práticas observadas.

O trabalho 3 ("Processos interativos entre professora ouvinte e estudantes visuais em aula de língua inglesa") é um relato de experiência sobre um projeto piloto no qual alunos de Letras Inglês experenciaram ensinar esta língua para uma turma mista de Letras Libras, dando bastante ênfase às integrações entre alunos surdos e ouvintes. $O$ trabalho analisou como esta integração contribuiu para o aprendizado de todos. 
ANAIS CBCS 2019 | 3 a 5 de outubro de 2019 | Centro Universitário Santo Agostinho - Teresina - P

No trabalho 4 ("O ensino e o aprendizado do inglês como língua estrangeira em uma escola bilíngue para surdos: reflexões sobre a prática pedagógica"), as pesquisadoras observaram as aulas das professoras de inglês de uma escola bilíngue para surdos e ao final realizaram questionários com os estudantes, a fim de coletarem respostas sobre a percepção deles a respeito dos métodos utilizados em sala de aula.

O trabalho 5 (“Letramento em língua estrangeira: a Libras no ensino da Língua inglesa como I3 para surdos"), ainda em andamento, é um Estudo de Caso que tem como sujeitos um aluno surdo, matriculado em escola regular, e a sua professora de Inglês. Foram observadas as aulas e os métodos empregados pela docente no processo de ensino-aprendizagem.

Tabela 2 - Resultados/Conclusões

\begin{tabular}{|c|c|c|}
\hline Autor & Resultados das Pesquisas & Conclusões \\
\hline $\begin{array}{l}\text { Yohanna Hemilly } \\
\text { Katleen Kühl e } \\
\text { Didiê Ana Ceni Denardi }\end{array}$ & $\begin{array}{l}\text { - Exposição do conteúdo de forma } \\
\text { oralizada; } \\
\text { - Poucas vezes a professora utilizou } \\
\text { gestos ou expressões faciais e } \\
\text { corporais para direcionar-se ao aluno } \\
\text { surdo; } \\
\text { - Professora se direcionava ao } \\
\text { intérprete, não ao aluno surdo; } \\
\text {-Quase não foi utilizado material } \\
\text { visual; } \\
\text { - Apenas dois alunos ouvintes sabiam } \\
\text { um pouco de Libras, portanto, quase } \\
\text { não havia interação com o aluno } \\
\text { surdo. }\end{array}$ & $\begin{array}{l}\text { - É necessário reconhecer a Libras } \\
\text { como L1 do surdo dentro da sala de } \\
\text { aula por ser a sua língua natural; } \\
\text { - A Libras é benéfica para o surdo, } \\
\text { possibilitando maior } \\
\text { desenvolvimento e novos } \\
\text { conhecimentos não apenas restritos } \\
\text { ao currículo escolar, mas também } \\
\text { abrindo os horizontes no que diz } \\
\text { respeito a sua visão de mundo; } \\
\text { - Há despreparo do professor de } \\
\text { Inglês para lidar com realidades } \\
\text { diferentes das idealizadas para o } \\
\text { ouvinte. }\end{array}$ \\
\hline $\begin{array}{l}\text { Jubileia Mendes de } \\
\text { Matos Coelho e } \\
\text { Dánie Marcelo de Jesus }\end{array}$ & $\begin{array}{l}\text {-Todas as colaboradoras desta } \\
\text { pesquisa se valeram, como recurso } \\
\text { didático e tecnológico, de } \\
\text { apresentação em slides, projetor } \\
\text { multimídia, quadro-branco e pincel, } \\
\text { com atividades fotocopiadas. Como } \\
\text { recurso metodológico, imagens } \\
\text { associadas a frases em inglês e } \\
\text { transcrição/tradução e/ou sinalização } \\
\text { em Libras; }\end{array}$ & $\begin{array}{l}\text { - As colaboradoras palmilharam as } \\
\text { práticas de letramento, em contexto } \\
\text { de ensino de inglês para surdos e de } \\
\text { acordo com a perspectiva dos } \\
\text { estudos de letramento; } \\
\text { - Concluíram que se aprende e se } \\
\text { ensina por meio da interação que } \\
\text { ocorre em sala de aula. }\end{array}$ \\
\hline
\end{tabular}




\begin{tabular}{|c|c|c|}
\hline & $\begin{array}{l}\text { - Os alunos, em sua maioria, } \\
\text { demonstraram interesse e } \\
\text { efetivamente participaram das } \\
\text { atividades propostas: perguntavam e } \\
\text { as professoras-alunas respondiam em } \\
\text { Libras; } \\
\text { - O ensino do conteúdo pautou-se na } \\
\text { associação entre frase em inglês, } \\
\text { tradução em Libras e interação entre } \\
\text { professor e alunos. Observou-se que, } \\
\text { além da atenção das professoras- } \\
\text { alunas com o aspecto gramatical, } \\
\text { houve ênfase a aspectos linguísticos } \\
\text { da Libras. }\end{array}$ & \\
\hline \multirow[t]{2}{*}{$\begin{array}{l}\text { Márcia de Moura } \\
\text { Gonçalves-Penna e } \\
\text { Simone de Jesus Padilha }\end{array}$} & $\begin{array}{l}\text { - Professoras utilizaram recurso visual } \\
\text { dos slides ou lâminas projetadas na } \\
\text { parede; } \\
\text { - Houve uso da Libras pelos } \\
\text { participantes; } \\
\text { - A apresentação de conteúdo foi de } \\
\text { fácil reconhecimento pelos } \\
\text { estudantes; } \\
\text { - A convivência numa sala de aula } \\
\text { mista em que houve o uso da Libras } \\
\text { por todos proporcionou maior } \\
\text { interação; } \\
\text { - As docentes evitaram a tradução } \\
\text { para o português, primando pela } \\
\text { associação entre palavra e imagem o } \\
\text { reconhecimento do sentido pelos } \\
\text { Alunos. }\end{array}$ & $\begin{array}{l}\text { - O uso da Libras em aula de inglês foi } \\
\text { a principal mediadora do ensino e da } \\
\text { aprendizagem nas interações entre } \\
\text { os participantes do curso; } \\
\text { - A interação professor e estudante } \\
\text { influenciou nos fatores afetivos } \\
\text { relacionados ao ensino e à } \\
\text { aprendizagem; } \\
\text { - A metodologia adequada foi } \\
\text { relevante às necessidades do visual e } \\
\text { possibilitou que houvesse interação } \\
\text { entre o professor, os alunos ouvintes } \\
\text { e os alunos visuais nas trocas de } \\
\text { aprendizagem; } \\
\text { - Os Projetos Pedagógicos dos Cursos } \\
\text { de Letras devem levar em conta a } \\
\text { formação do professor para que } \\
\text { possa atuar em sala de aula mista e, } \\
\text { se possível, sinalizar ele mesmo em } \\
\text { Libras para melhor interação com o } \\
\text { visual (ainda que tenha um } \\
\text { intérprete). }\end{array}$ \\
\hline & $\begin{array}{l}\text { - As pesquisadoras observaram que } \\
\text { na escola bilíngue não havia livros de } \\
\text { inglês específicos para os alunos } \\
\text { surdos, fornecidos pelo Ministério da } \\
\text { Educação. Diante disso, as } \\
\text { professoras desenvolviam o material } \\
\text { didático que usavam em sala de aula; }\end{array}$ & $\begin{array}{l}\text { - Os estudantes gostam de aprender } \\
\text { inglês, mas sentem dificuldades. } \\
\text { Essas dificuldades mostraram ser } \\
\text { provenientes do processo de ensino, } \\
\text { que dificulta ao aluno o acesso aos } \\
\text { conteúdos devido ao não domínio da } \\
\text { Libras por parte do professor, ou }\end{array}$ \\
\hline
\end{tabular}


ANAIS CBCS 2019 | 3 a 5 de outubro de 2019 | Centro Universitário Santo Agostinho - Teresina - P

\begin{tabular}{|c|c|c|}
\hline $\begin{array}{l}\text { Edvanilda Antônia } \\
\text { Borges e } \\
\text { Layane Rodrigues de } \\
\text { Lima }\end{array}$ & $\begin{array}{l}\text { - Havia imagens em todos os } \\
\text { conteúdos, o que facilitava a } \\
\text { compreensão do assunto pelos } \\
\text { alunos surdos, que faziam as } \\
\text { atividades sem dificuldades; } \\
\text { - A professora que tinha domínio de } \\
\text { Libras fez uso de diferentes } \\
\text { estratégias de ensino, considerando } \\
\text { os variados estilos de aprendizagem e } \\
\text { de proficiência no inglês de cada } \\
\text { aluno surdo; } \\
\text { - A professora que não conhecia a } \\
\text { Libras não utilizava metodologia } \\
\text { adequada para o ensino de alunos } \\
\text { surdos; }\end{array}$ & $\begin{array}{l}\text { ainda, pela falta de conhecimento do } \\
\text { inglês pelo intérprete; } \\
\text { - Há escassez de material didático } \\
\text { próprio para esse ensino; } \\
\text { - O acesso tardio a uma metodologia } \\
\text { que considere a cultura visual do } \\
\text { surdo, prejudica o seu } \\
\text { desenvolvimento escolar; } \\
\text { - O domínio da Libras e o } \\
\text { conhecimento das peculiaridades da } \\
\text { cultura surda, levou uma das } \\
\text { professoras pesquisadas a } \\
\text { desenvolver estratégias de ensino } \\
\text { mais adequadas. }\end{array}$ \\
\hline $\begin{array}{l}\text { Gideão da Silva } \\
\text { Nascimento dos Santos } \\
\text { e } \\
\text { Francisca Maria } \\
\text { Cerqueira da Silva }\end{array}$ & $\begin{array}{l}\text { - Ausência de intérprete de Libras, } \\
\text { pois não existe esse profissional na } \\
\text { rede de ensino do município; } \\
\text { - Em nenhum momento houve o } \\
\text { apoio da Libras para compreensão de } \\
\text { conceitos, pois a Libras não é uma } \\
\text { língua comum entre professora e } \\
\text { aluno surdo, e entre aluno surdo e } \\
\text { colegas de sala; } \\
\text { - Não foram utilizados recursos } \\
\text { pedagógicos imagéticos adequados à } \\
\text { especificidade do surdo (com o uso } \\
\text { da Libras) nesse espaço, para o } \\
\text { ensino da língua inglesa, pois a } \\
\text { professora não } \\
\text { passou por formação para trabalhar } \\
\text { com essas especificidades da } \\
\text { educação de surdos. }\end{array}$ & $\begin{array}{l}\text { - O ensino dessa terceira língua para } \\
\text { os surdos deve lançar mão de } \\
\text { diversas estratégias das quais pelo } \\
\text { menos três podemos destacar aqui: } \\
\text { ensino contextualizado, uso da } \\
\text { primeira língua do surdo como apoio, } \\
\text { uso de recursos imagéticos; } \\
\text { - São necessários arranjos que } \\
\text { incluem múltiplas ações de } \\
\text { adequações pedagógicas envolvendo } \\
\text { a Libras, múltiplos profissionais } \\
\text { (professores bilíngues, intérpretes } \\
\text { Libras-LP/LP-Libras, professores de } \\
\text { Língua Portuguesa-LP como L2) e } \\
\text { múltiplos contextos que envolvem as } \\
\text { várias instituições sociais (como a } \\
\text { família e a escola), além dos } \\
\text { contextos estritamente escolares } \\
\text { (como a sala de aula comum, e o } \\
\text { espaço de AEE). }\end{array}$ \\
\hline
\end{tabular}

Fonte: tabela elaborada pelas autoras

Percebemos, no trabalho 1, que a professora, apesar de estar lecionando em sala mista (alunos surdos e ouvintes), mantinha os métodos e técnicas de ensino apropriadas a alunos 
ANAIS CBCS 2019 | 3 a 5 de outubro de 2019 | Centro Universitário Santo Agostinho - Teresina - PI

ouvintes (exposição do conteúdo de forma oralizada, com pouco material visual). Também foi detectado que ela se dirigia à intérprete de Libras e não ao aluno.

Essa postura tende a isolar o discente surdo, pois este fica excluído do processo de ensino. Sobre isso, não podemos esquecer das atribuições do intérprete de Libras contidas na lei $\mathrm{n}^{\circ} 12.319$, de 10 de setembro de 2010 , artigo $6^{\circ}$, inciso II:

interpretar, em Língua Brasileira de Sinais - Língua Portuguesa, as atividades didático-pedagógicas e culturais desenvolvidas nas instituições de ensino nos níveis fundamental, médio e superior, de forma a viabilizar o acesso aos conteúdos curriculares.

Ou seja, ele é o intérprete e não o professor, portanto, o docente não pode se abster do seu papel de educador, independente da necessidade especial do seu aluno.

Ainda sobre a situação observada na pesquisa, Campos $(2012$, p.41) nos lembra que nos casos "nos quais o professor desconhece a Libras, ele ministrará o conteúdo pedagógico apenas na língua majoritária (a língua portuguesa), de sorte a desresponsabilizar-se do aluno surdo, uma vez que não sabe o que fazer com tal aluno".

No trabalho 2, as estagiárias observadas lançaram mão de técnicas e métodos que possibilitaram a participação nas aulas e o aprendizado dos alunos surdos: materiais visuais, slides, sinalização em Libras, ou seja, houve uma preocupação real em incluir estes discentes na prática educativa e, com isso, observou-se que eles mostravam-se mais motivados e interessados em participar das aulas de inglês. As docentes também evitaram traduzir do inglês para o português; ao invés disso, traduziam do Inglês para a Libras, visto que esta é a L1 dos surdos, e o português escrito para estes alunos normalmente é de difícil compreensão, já que, segundo Santana e Carneiro (2012, p.61), o fato de as crianças surdas "não contarem com a Língua Portuguesa na modalidade oral, o processo de aquisição da escrita apresenta diferenças em relação ao da criança ouvinte, tanto no ritmo como no percurso em direção à escrita convencional".

O trabalho 3 corrobora os resultados do trabalho 2, especialmente, nos argumentos de que os professores devem ser conhecedores da Libras, utilizando técnicas de ensino apropriadas aos alunos surdos. Os pesquisadores sugerem ainda que os estudantes ouvintes devem também aprender a Língua de Sinais para favorecerem a inclusão de alunos surdos, melhorando o aprendizado e a participação efetiva de todos os alunos no processo de ensino- 
ANAIS CBCS 2019 | 3 a 5 de outubro de 2019 | Centro Universitário Santo Agostinho - Teresina - P

aprendizagem. Neste ponto, temos a contribuição de Campos (2012, p.51), a qual assevera que:

Ao fazer uso dessa língua visuomotora, nós a revestimos de humanidade e fazemos dela um instrumento fundamental para a construção de um estudante surdo. Se concebermos a escola como um espaço no qual partilhamos conhecimento, a língua passará a ser um mediador, sem o qual as relações caem no vazio, o qual determinará não só a história de cada membro da comunidade surda, mas também da história da educação de surdos que pretendemos escrever daqui para frente.

O trabalho 4 compara as metodologias de ensino de duas professoras de Inglês: uma com conhecimento em Libras e a outra sem este conhecimento. Os resultados mostram claramente que a professora com fluência em Libras promovia um ensino mais eficiente para os seus alunos surdos, ao passo que a professora sem esta fluência não conseguia os mesmos resultados nas suas turmas.

Por fim, o trabalho 5 traz resultados que vêm ao encontro do que já foi discutido anteriormente: os professores que não possuem fluência em Libras e treinamento para trabalharem com crianças e jovens especiais, quando se deparam com alunos surdos em suas salas de aula, não adaptam os seus métodos e técnicas de ensino. Com isso, a escola regular que se propõe ser "inclusiva", serve apenas como um local de "socialização" do surdo, como bem nos lembra Campos (2012, p.46):

não estaríamos sucateando o espaço escolar, quando o restringimos a espaço de relações? Estas relações não acontecem, também, em outros locais e espontaneamente?.... Pelo senso comum, estar junto já garantiria ao surdo um privilégio, visto que não existe a expectativa de que esse sujeito tenha uma formação acadêmica que Ihe permita desempenhar diferentes papéis nas relações profissionalizantes e familiares entre outras.

\section{CONSIDERAÇÕES FINAIS}

Após análise dos cinco estudos sobre o ensino de Língua Inglesa para estudantes surdos, concluímos que a legislação é apenas o primeiro passo para a inclusão desses alunos 
ANAIS CBCS 2019 | 3 a 5 de outubro de 2019 | Centro Universitário Santo Agostinho - Teresina - PI

nas escolas regulares. Realmente ocorreu um avanço nessa política educacional, com a regulamentação da profissão de intérprete de Libras; com a obrigatoriedade do ensino de Libras nos cursos de Educação Especial, de Fonoaudiologia e de Magistério; com a oferta dos cursos de Licenciatura em Letras Libras nas universidades. No entanto, quando adentramos nas salas de aula das escolas regulares, notamos que mesmo naquelas em que há alunos surdos matriculados não é garantida a presença do intérprete, ficando esse aluno excluído do processo de ensino-aprendizagem.

Descobrimos também que há escassez de materiais didáticos apropriados a esses alunos que necessitam de materiais mais visuais. Além disso, mesmo nas escolas bilíngues encontramos professores que não têm conhecimento da Libras e, pelos resultados das pesquisas analisadas, vimos o quanto este fator influencia na interação com o aluno surdo, pois, quando o docente tem treinamento adequado, ele utiliza técnicas e métodos mais apropriados para a necessidade do seu educando.

Precisamos enfatizar que o conhecimento de Libras pelos estudantes ouvintes possibilita uma melhor interação do aluno surdo ao ambiente escolar, contribuindo para o aprendizado e socialização deste. Vale lembrar que os surdos normalmente vêm de famílias ouvintes, as quais, na maioria das vezes, não têm conhecimento da língua de sinais, comunicando-se com eles através de gestos; esta situação gera uma comunicação extremamente pobre e influencia na construção do cognitivo da pessoa surda; por isso, a importância de a escola ser um local verdadeiramente inclusivo. A Libras, por seu turno, não pode ser vista como a "Língua do surdo", mas, sim, como a outra língua oficial do Brasil.

\section{REFERÊNCIAS}

ATALLAH, Alvaro Nagib; CASTRO, Aldemar Araujo. Revisão Sistemática e Metanálises em: Evidências para Melhores Decisões Clínicas. São Paulo. Lemos Editorial, 1998.

BRASIL. Ministério da Educação. Lei de Diretrizes e Bases da Educação Nacional. LDB 9.394, de 20 de dezembro de 1996. Brasília, 1996.

. Lei no 10.436, de 24 de abril de 2002. Dispõe sobre a Língua Brasileira de

Sinais - Libras e dá outras providências. Brasília, 2002. 


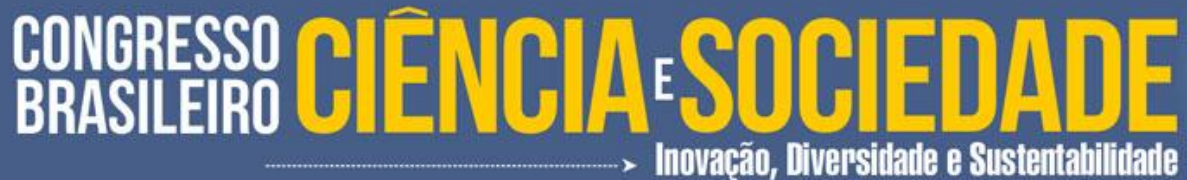

ANAIS CBCS 2019 | 3 a 5 de outubro de 2019 | Centro Universitário Santo Agostinho - Teresina - P

Decreto no 5.626, de 22 de dezembro de 2005. Regulamenta a lei no 10.436, de 24 de abril de 2002, que dispõe sobre a língua brasileira de Sinais - Libras. Brasília, 2005.

Lei no 12.319, de 10 de setembro de 2010. Regulamenta a profissão de Tradutor e Intérprete da Língua Brasileira de Sinais - LIBRAS. Brasília, 2010. Disponível em: http://www.planalto.gov.br/ccivil_03/_ato2007-2010/2010/lei/l12319.htm. Acesso em 09/09/2019.

. INSTITUTO BRASILEIRO DE GEOGRAFIA E ESTATÍSTICA. Disponível em: <https://www.ibge.gov.br/estatisticas/sociais/populacao/9662-censo-demografico2010.html?edicao=9749\&t=resultados $>$. Acesso em: 8 ago. 2019.

CAMPOS, Sandra Regina Leite. O papel da língua de sinais na constituição do surdo como estudante. In: GIROTO, Claudia Regina; MARTINS, Sandra Eli Sartoreto de Oliveira; BERBERIAN, Ana Paula (Org.). Surdez e educação inclusiva. São Paulo: Cultura Acadêmica; Marília: Oficina Universitária, 2012. pp 37 a 53.

FREIRE, Paulo. Conscientização: teoria e prática da libertação: uma introdução ao pensamento de Paulo Freire. Trad. Kátia de Mello e Silva. Rev. técnica Benedito Eliseu Leite Cintra. São Paulo: Cortez \& Moraes, 1979.

SANTANA, Ana Paula; CARNEIRO, Maria Sylvia Cardoso. O processo de avaliação da aprendizagem do surdo no contexto da escola regular. In: GIROTO, Claudia Regina; MARTINS, Sandra Eli Sartoreto de Oliveira; BERBERIAN, Ana Paula (Org.). Surdez e educação inclusiva. São Paulo: Cultura Acadêmica; Marília: Oficina Universitária, 2012. pp 55 a 77. 